\author{
Cadernos de \\ ESTUDOS LINGUIISTICOS - (58.2), Campinas, pp. 277-298 - mai./ago. 2016
}

\title{
O APORTE DAS FONTES INQUISITORIAIS PARA UMA HISTÓRIA DA DIFUSÃO SOCIAL DA LEITURA E DA ESCRITA NO BRASIL COLONIAL
}

\author{
TÂNIA LOBO ${ }^{1}$ \\ ANA SARTORI ${ }^{2}$ \\ RODRIGO MOTA SOARES ${ }^{3}$
}

\begin{abstract}
RESUMO: O Brasil é um país de escolarização em massa e imprensa tardias. Paradoxalmente, é através dos espaços institucionais formais, sobretudo a escola, que se tem buscado traçar a história da distribuição social da leitura e da escrita na sociedade brasileira, não necessariamente, tomando tal questão como foco - em uma abordagem global, de caráter sociológico e demográfico -, mas apenas dando pistas para a sua compreensão, através, por exemplo, da história das políticas educacionais, do mapeamento dos métodos de ensino ou ainda da história da construção dos materiais didáticos, enfatizando-se, na maioria das vezes, o analfabetismo da população. Identifica-se, portanto, uma carência de investigações, que, contemplando novas fontes, novos métodos, novos espaços, novos atores, abordem a multifacetada questão da distribuição social da leitura e da escrita na sociedade brasileira desde as suas origens coloniais. Buscando contribuir para preencher tal lacuna, o projeto Leitura e escrita aos olhos da Inquisição objetiva traçar, a partir da análise das fontes documentais produzidas pelas visitações do Santo Ofício, um quadro aproximativo da faculdade das letras na América colonial portuguesa. Neste artigo, apresentam-se resultados parciais das pesquisas desenvolvidas no âmbito do referido projeto, analisandose o conjunto de depoimentos prestados e assinados perante o Santo Ofício constantes do Livro das Denunciações e do Livro das Confissões e Reconciliações, escritos ambos quando da segunda visitação da Inquisição à Capitania da Bahia, entre 1618 e 1620. Cruzando a variável binária assinante versus não assinante com as variáveis sexo, origem geográfica do depoente, etnia, condição religiosa e categoria socioocupacional, esboça-se um perfil sociológico dos letrados nos primórdios da colonização, contexto marcadamente multilíngue e de quase ausência de instituições voltadas à alfabetização. Ao abarcar a questão da distribuição social da leitura e da escrita no período colonial, abarca-se uma das questõeschave para a compreensão da história social do português brasileiro.
\end{abstract}

Palavras-chave: Inquisição no Brasil; Distribuição social da leitura e da escrita; História social do português brasileiro.

ABSTRACT: Brazil is a country of tardy mass education and press. Paradoxically, it is through formal institutional spaces, especially the school, where the history of the social distribution of reading and writing in the Brazilian society has been delineated, but, not necessarily, taking such a question as focus - in a global approach, of a sociological and demographic nature -, only offering hints for its comprehension through, for instance, the history of educational policies, the mapping of teaching methods and also the history of the production of teaching materials, emphasizing, most of the time, the population's illiteracy. Therefore, it is identified a shortage of investigations which, once it contemplates new sources, new methods, new spaces, new players, it approaches the multifaceted issue of social

\footnotetext{
${ }^{1}$ tanlobo@gmail.com

2 anasartorii@hotmail.com

${ }^{3}$ rodrigomotasoares@gmail.com
} 
distribution of reading and writing in the Brazilian society since its colonial origins. Attempting to fill up such a gap, the project Reading and wiring before the eyes of the Inquisition, based on the analysis of documental sources produced by visitations of the Holy Office, seeks to build up an approximate picture of the faculty of letters in the Portuguese colonial America. Partial results of research studies developed within the scope of the aforementioned project are presented in the article, as well as an analysis of the group of testimonies given and signed before the Holy Office as part of the Book of Denunciations and the Book of Confessions and Reconciliations, both written during the second visit of the Inquisition to the Captaincy of Bahia, in between 1618 and 1620. Crossing the signing binary variable versus the non-signing variable with the variables sex, geographical origin, ethnicity, religious condition, and socio-occupational category of the deponent, it is conceived a sociological profile of the literate in the early years of the colonization, a massively multilingual context with an almost total absence of institutions engaged with literacy. Once the question of the social distribution of reading and writing in the colonial period is discussed, it is thus tackled one of the key questions for the comprehension of the social history of Brazilian Portuguese.

Keywords: Inquisition in Brazil; Social distribution of reading and writing; Social history of Brazilian Portuguese.

\section{INTRODUÇÃO}

Quando se aborda a história social linguística do Brasil, com o objetivo de delinear um sistema de questões articuláveis à formação do português brasileiro, destacam-se mudanças estruturais que, na longa duração, ocorreram principalmente em dois níveis (cf. Houaiss, 1985 e MATTOS \& SILVA, 1998): (i) o nível referente à história das sucessivas distribuições das populações e das suas respectivas línguas; (ii) o nível referente à história da distribuição social da leitura e da escrita.

A partir do primeiro, busca-se dar conta do fato de que o português brasileiro é uma língua que emergiu em contexto multilíngue, sendo, portanto, o contato linguístico um dos aspectos constitutivos da sua formação. A partir do segundo, articulado, obviamente, ao primeiro, busca-se a compreensão das variedades do português brasileiro que configuram a complexa teia sociolinguística do Brasil contemporâneo, definida por um continuum, em cujos extremos se situam, por um lado, normas linguísticas socialmente mais prestigiadas - urbanas, supostamente mais unitárias e descendentes diretas do português europeu, além de moldadas sob o influxo do padrão normativo de escrita difundido via escolarização - e, por outro lado, normas linguísticas socialmente mais estigmatizadas - rurais, supostamente mais diversificadas e descendentes diretas do português falado como segunda língua por índios e negros, os quais, juntamente com seus descendentes, do século XVI a meados do XIX, sempre constituíram o segmento maioritário da população brasileira e até aproximadamente meados do século XX estiveram, em sua maioria, à margem do sistema formal de escolarização.

Relativamente ao segundo nível, Galvão (2010), em um levantamento da produção acadêmica sobre a história da cultura escrita no Brasil, feito a partir do banco de teses da CAPES, o qual registra teses e dissertações defendidas desde 1987, afirma: 


\begin{abstract}
[...] não temos (ou pelo menos não localizamos), no caso brasileiro, uma produção, tal como ocorre na Europa ou nos Estados Unidos, que permita situar, em escala societal, a presença da alfabetização e do letramento ao longo desses cinco séculos de história do país. No levantamento realizado, não foi localizado nenhum estudo que pudesse ser classificado estritamente como pertencente a essa linha de investigação. Portanto, no país não há um mapeamento da distribuição social da alfabetização anterior ao primeiro censo demográfico, que foi realizado em 1872. Não sabemos, por exemplo, quem eram e onde estavam aqueles que sabiam ler e escrever ${ }^{4}$ (GALVÃO, 2010, pp. 241-242).
\end{abstract}

As razões apontadas pela autora para essa total ausência seriam, em primeiro lugar, a inexistência, na maior parte do país, de acervos organizados que permitissem reconstruir séries documentais fundamentais para a realização de uma história demográfica e quantitativa da alfabetização e do letramento e, em segundo lugar, o fato de, no Brasil, as pesquisas sobre tal campo estarem predominantemente concentradas nas faculdades de Educação e de Letras, cujos pesquisadores seriam, na maior parte dos casos, ou inexperientes no trabalho de prospecção arquivística ou sem a necessária formação paleográfica para o enfrentamento da leitura de fontes manuscritas; além disso, observa ainda que os vinculados às faculdades de História apenas excepcionalmente teriam a história da cultura escrita como objeto de estudo.

Para além das questões supostamente impeditivas ou inibidoras locais, brasileiras, como as referidas acima, importa discutir um aspecto metodológico de ordem mais geral: como mapear a distribuição social da leitura e da escrita em períodos pré-censitários ou proto-censitários, como o são a Era Moderna e, portanto, todo o período colonial e quase todo o período imperial brasileiros? Como mensurar o crescimento das taxas de alfabetização, a maior circulação da escrita a mão ou impressa, ou mesmo a difusão da leitura silenciosa e na intimidade, mudanças que marcaram os séculos XVI, XVII e XVIII na Europa ocidental?

$\mathrm{Na}$ Europa anglo-saxã e francesa, como mostram Castillo Gómez e Sáez (1994, pp. 134-135), a inquietação historiográfica por uma abordagem social da escrita emerge na década de 60, inicialmente entre antropólogos e historiadores, preocupados, respectivamente, com os impactos decorrentes da introdução da escrita nas sociedades e com o quanto as capacidades de ler e escrever se estendiam nas sociedades do Antigo Regime. Destacam ainda que, paralelamente à, ou até mesmo antes da, produção anglo-saxã e francesa, também na Itália, paleógrafos de formação marxista passaram a defender um projeto de investigação sobre a escrita que transcendesse a sua concepção enquanto mero sistema gráfico, procurando abordar suas distintas funções e suas consequentes práticas materiais, sempre em referência às respectivas sociedades históricas. Em outros termos, promoveram a expansão do método paleográfico, tradicionalmente restrito às questões $o$ que se escreveu? ("leitura correta"), quando se escreveu? ("datação"), onde se escreveu? ("localização") e como se escreveu? ("tipos gráficos"), introduzindo no seu labor duas novas questões: quem escreveu? ("difusão social") e por que se escreveu? ("função social").

\footnotetext{
${ }^{4}$ Grifo nosso.
} 
Tal inquietação vai coincidir, justamente, com a "revolução quantitativa" da historiografia contemporânea - conhecida por história quantitativa ou história serial -, que, apesar de assentada na (discutível?) ideia de ser possível quantificar o cognoscível, se justificava ideologicamente, como destaca Langelli (1996, p. 88),

por la posibilidad que ofrecía de recuperar para el conocimiento histórico no sólo a los protagonistas sino también a los individuos anónimos, no sólo los acontecimientos espectaculares sino también los fenómenos de fondo, repetitivos, de masa.

Num primeiro momento, portanto, as pesquisas sobre a alfabetização e o letramento no Ocidente durante a Era Moderna apoiaram-se, sobretudo, em análises quantitativas, mais especificamente, no cômputo de séries de assinaturas deixadas em fontes diversas, tais como os registros de casamento e de batismo, os testamentos, os depoimentos prestados em tribunais eclesiásticos, contrastando-se indivíduos capazes e incapazes de assinar o próprio nome. Foram as assinaturas largamente utilizadas, por serem quase que exclusivamente capazes de fornecer, ao longo de séculos, grandes quantidades de dados, socialmente diversificados, para grande parte do mundo ocidental (cf. LANGELI, 1996), atentando uns autores mais outros menos para a ressalva de que não devessem ser consideradas de forma ingênua e acrítica, não só porque, nas sociedades do Antigo Regime, a aprendizagem da escrita sucedia a da leitura e envolvia apenas uma parte das crianças - todos os que assinavam o nome sabiam ler, mas nem todos os que liam sabiam assinar o nome -, mas também porque, entre os que sabiam assinar, nem todos escreviam, podendo ser a assinatura o último estágio de uma aprendizagem cultural ou o que dela restou (cf. CHARTIER, 2004).

Os primeiros balanços sobre a produção europeia e norte-americana na área datam da década de 80, quando, então, já era possível não só delinear o perfil de duas gerações, mas também se divisava a emergência de uma terceira. Com base em Graff (1987) $)^{5}$, afirmam Castillo Gómez e Sáez (1994) que a primeira geração, se teve o mérito de estabelecer as primeiras séries cronológicas da difusão da alfabetização, de identificar as fontes necessárias para seu estudo, principalmente as de tipo quantitativo, de iniciar os estudos comparativos a partir da variável assinatura e mesmo de apresentar, às vezes de forma especulativa, as suas consequências cognitivas e sociais, pecou, por outro lado, por interpretações um tanto unívocas dos processos da alfabetização, como a identificação entre alfabetização e desenvolvimento socioeconômico ou político, o chamado "mito da alfabetização". A segunda geração caracterizou-se já por maior aproveitamento das séries quantitativas e por maior entendimento da complexidade dos processos de alfabetização e letramento, atribuindo maior importância à contextualização dos mesmos, ao reconhecer a influência dos fatores ideológico-culturais na conformação de diversos modelos históricos de alfabetização, ao investigar o

${ }^{5}$ GRAFF, Harvey J. Gli studi di storia dell’alfabetizzazione: verso la terza generazione, «QS», ano XXII, 64/1 (1987), pp. 203-222; «Interchange», 17/2 (1986), p. 122-134. apud Castillo Gómez e Sáez (1994). 
Gadernos de ESTUDOS LINGUIISTICOS (58.2) - mai./ago. 2016

fenômeno tanto em seus aspectos práticos - escrita e leitura -, como em seus efeitos psicológicos, enfatizando as limitações do quantitativismo. Finalmente, a terceira geração, que destaca a necessidade dos estudos comparativos, para o que se torna decisiva a importância do contexto, conduzindo à etnografia da alfabetização e do letramento; a necessidade da crítica dos próprios conceitos de alfabetização e letramento, tendo-se em conta as representações, as práticas culturais e os discursos que a elas se referem; a necessidade do aprofundamento teórico-metodológico e do investimento em uma abordagem interdisciplinar de análise, suplantando a perspectiva da história da alfabetização e do letramento, em favor da perspectiva da alfabetização e do letramento na história; em suma, da alfabetização para as alfabetizações; do letramento para os letramentos.

\section{PARA UMA HISTÓRIA DA DIFUSÃO SOCIAL DA LEITURA E DA ESCRITA NO BRASIL COLONIAL: RESULTADOS PARCIAIS SOBRE A CAPITANIA DA BAHIA NO SÉCULO XVII}

Uma das justificativas apontadas como impeditivas ou inibidoras para a realização de uma história demográfica e quantitativa da alfabetização e do letramento no Brasil - a inexistência, no país, de acervos organizados que permitissem reconstruir séries documentais fundamentais - pode ser facilmente questionada, já que milhões de páginas escritas sobre e no Brasil colonial não permaneceram aqui à mercê de cupins, de destruição por agentes humanos ou de uma política arquivística precária, mas estão preservadas em arquivos europeus, dentre os quais se destaca, em Portugal, o Arquivo Nacional da Torre do Tombo, onde se conservam, por exemplo, documentos produzidos pelas visitações da Inquisição ao Brasil. As fontes da Inquisição, já abordadas por autores como Rodríguez \& Bennassar (1978) e Marquilhas (2000), em análises sobre níveis de alfabetismo na Espanha e em Portugal, respectivamente, ainda não tinham sido utilizadas com o mesmo fim no Brasil. É isto que se tem levado a cabo no âmbito do projeto Leitura e escrita aos olhos da Inquisição, com o objetivo de contribuir para o mapeamento da distribuição social da alfabetização no período anterior ao censo demográfico de 1872. Neste artigo, serão apresentados apenas resultados parciais das pesquisas desenvolvidas no âmbito do referido projeto, especificamente referentes à Capitania da Bahia, no século XVII.

\subsection{Os livros da segunda visitação do Santo Ofício à Capitania da Bahia, 1618-1620}

O Tribunal do Santo Ofício atuou na Península Ibérica ao longo de três séculos e meio e sua ação ainda se expandiu para áreas não europeias dominadas por Portugal e Espanha. Na América Espanhola, foram instalados tribunais no México e em Lima em 1569-1570 e também em Cartagena de Índias em 1610. Quanto ao império colonial português, as áreas afetadas foram Goa, onde um tribunal atuou de 1560 a 1774 e de 1778 a 1812, e ainda a Madeira, os Açores, a 
LOBO, SARTORI \& SOARES - O aporte das fontes inquisitoriais para uma história da ...

Angola e o Brasil, que não contaram com a instalação de tribunais, mas foram alvo da justiça itinerante, as chamadas visitações. À América Portuguesa, sob a tutela do Tribunal de Lisboa, foram feitas quatro: às capitanias da Bahia, Pernambuco, Itamaracá e Paraíba nos anos de 1591-1595; novamente à capitania da Bahia nos anos de 1618-1620; às capitanias do Sul nos anos de 1627-1628 e, finalmente, ao Grão-Pará nos anos de 1763-1769.

A segunda visitação ao Brasil foi conduzida por Marcos Teixeira, incumbido não só de visitar a cidade do Salvador da Bahia de Todos os Santos e seu Recôncavo, mas também Angola. Dos registros feitos pelo notário Manuel Marinho, conhecemse apenas dois livros 6 . O primeiro a vir à luz foi o de Denunciações, em edição feita em 1936 por Rodolfo Garcia, publicada nos Anais da Biblioteca Nacional do Rio de Janeiro ${ }^{7}$; o segundo foi o de Confissões e Reconciliações, dado a conhecer por Eduardo de Oliveira França e Sônia Siqueira, em edição publicada em 1963, nos Anais do Museu Paulista.

São tais livros fontes de valor inestimável para o que aqui se propõe, porque cada um dos depoimentos que os compõem é precedido por informações que permitem uma análise sociológica do perfil dos depoentes - informações tais como o próprio nome, a filiação, a idade, a naturalidade, o local de residência, a cor/ etnia, a ocupação, o estado civil e a condição religiosa - e, ao final, o denunciante ou confitente assinava alfabeticamente o seu depoimento, caso fosse capaz de fazê-lo ${ }^{8}$. Veja-se, na Figura 1, a ilustração de um depoimento:

${ }^{6}$ Comparativamente à primeira visitação, da qual já se localizaram sete dos nove livros produzidos, o número de livros conhecidos da segunda visitação é bastante modesto.

${ }^{7}$ Trata-se de uma edição parcial, que se limita às denúncias, sem avançar para a parte do códice em que testemunhas são chamadas para depor.

${ }^{8}$ Além do depoente, assinavam o inquisidor Marcos Teixeira e dois padres da Companhia de Jesus que o acompanhavam. Após assinarem, o notário redigia um breve texto, apontando se o Santo Ofício tomaria por verdade o depoimento prestado e, então, voltavam a assinar o inquisidor e os padres. 


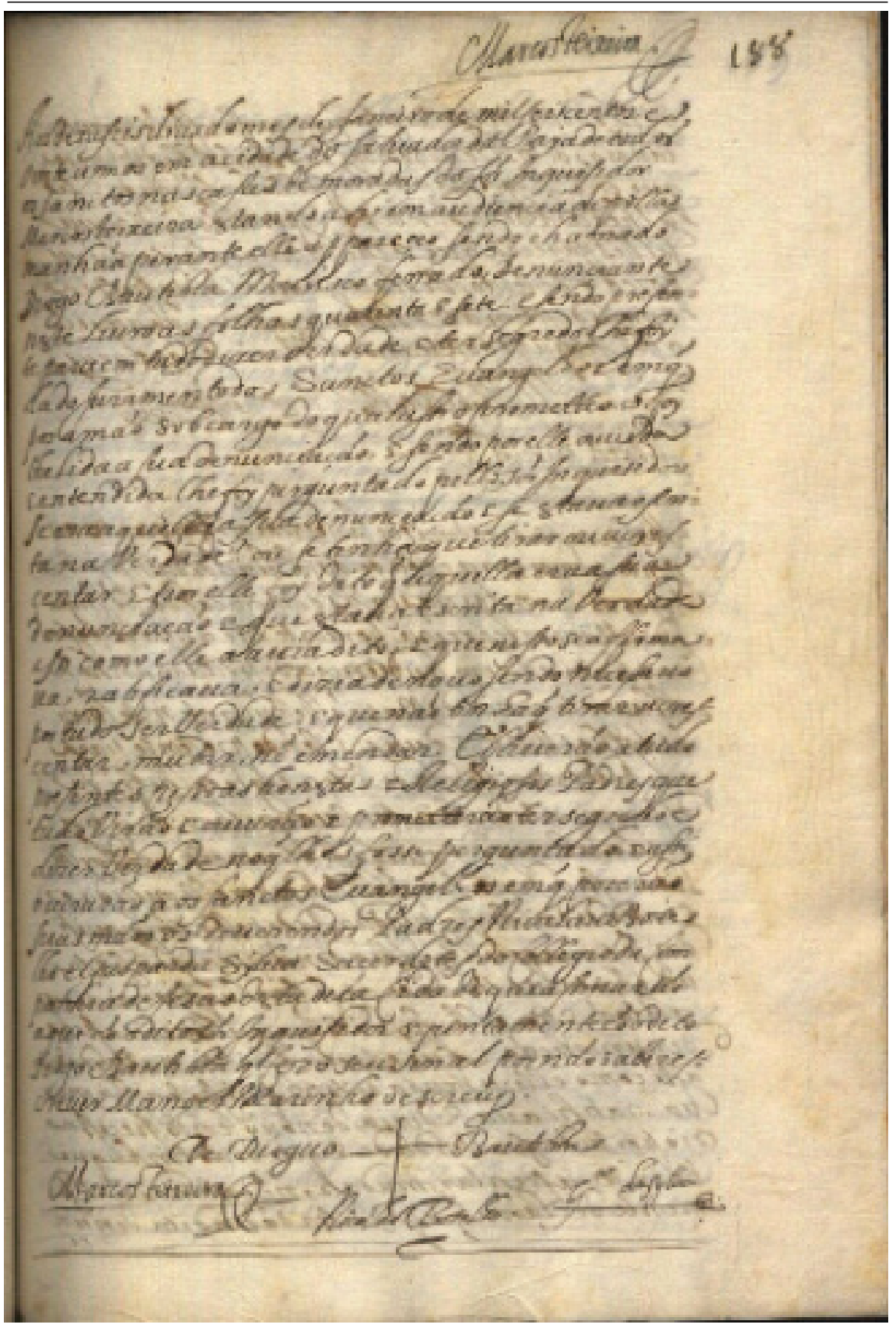

Figura 1: Fac-símile do depoimento de Diogo Batista 
LOBO, SARTORI \& SOARES - O aporte das fontes inquisitoriais para uma história da ...

Quanto aos depoentes incapazes de assinar alfabeticamente o próprio nome, quer fossem homens, quer fossem mulheres, o mais comum foi fazerem uma cruz, sinal que era ladeado pelo registro do seu nome, feito pelo notário do Santo Ofício, como se pode observar na Figura 1, acima, em que o notário, inclusive, acrescenta o "de", informando tratar-se, no caso em questão, da cruz de Diogo Batista.

\subsection{Descrição e Análise dos dados}

Passa-se a seguir à descrição e análise dos dados, adotando-se o procedimento de cotejar sistematicamente os resultados aqui apresentados com os de Lobo e Oliveira (2013), referentes aos anos de 1591-1592 para a Capitania da Bahia, com os de Sartori (2016), referentes aos anos de 1593-1594 para as Capitanias de Pernambuco, Itamaracá e Paraíba, e, de forma menos sistemática, com os obtidos por Marquilhas (2000), para Portugal ao longo de todo o século XVII. Os estudos que serão cotejados também analisaram fontes inquisitoriais.

\subsubsection{Resultados gerais}

Ainda que não com a mesma representatividade, pessoas de diversos estratos da população - homens, mulheres, brancos, mamelucos, mulatos, índios, negros, senhores de engenho, lavradores, artesãos, mercadores, padres, estudantes, feitores, escravos, soldados, criados, cristãos-novos, cristãos-velhos, portugueses, brasileiros, africanos... - compareceram à Mesa da Inquisição para denunciar crimes contra a fé católica ou confessar as próprias culpas.

Colheram-se 232 depoimentos, sendo 159 registrados no Livro das Denunciações e 73 registrados no Livro das Confissões e Reconciliações. Todavia, como foram identificados nove confitentes que também se apresentaram à Mesa na condição de denunciantes (ou de testemunhas, chamadas para confirmar a veracidade ou não das denúncias), foram esses indivíduos subtraídos do total dos confitentes, o que confere ao corpus, um total de 223 indivíduos, sendo 159 $(71,3 \%)$ denunciantes e testemunhas ${ }^{9}$ e $64(28,7 \%)$ confitentes.

A quantidade de depoentes do Livro das Denunciações é maior que o dobro da presente no Livro das Confissões e Reconciliações. O percentual de assinantes é equivalente em ambos os livros, correspondendo a $84,4 \%$ e $82,4 \%$, respectivamente. Reunidos os dados dos dois livros, obtém-se um total de $83 \%$ assinantes, ou seja, 4 a cada 5 depoentes sabiam assinar o próprio nome. Tal percentual é não só alto, mas, inclusive, superior ao de 69,5\%, obtido por Lobo e Oliveira (2013), ao de 76\%, obtido por Sartori (2016), e também ao de 60,1\%, obtido por Marquilhas (2000).

\footnotetext{
${ }^{9}$ Doravante, não se fará distinção entre denunciantes e testemunhas com depoimento registrado no Livro de Denunciações, passando todos a ser referidos como denunciantes.
} 
Cadernos de ESTUDOS LINGUIISTICOS (58.2) - mai./ago. 2016

A seguir, se procederá ao cruzamento da variável binária, assinante versus não assinante, com as variáveis sociológicas, para o delineamento do perfil dos sujeitos da amostra e, consequentemente, melhor compreensão do que representa, na Bahia de então, uma taxa tão elevada de assinaturas.

\subsubsection{Repartição da amostra por sexo}

O primeiro aspecto a ter em conta é que a amostra está desigualmente repartida entre homens e mulheres: dos 232 depoimentos analisados, 201 (90,1\%) são de homens e $22(9,9 \%)$ de mulheres, ou seja, apenas um entre cada dez indivíduos registrados era mulher. Mesmo não atingindo um nível tão baixo como o que aqui se apresenta, deve-se notar que, ao menos para os séculos XVI e XVII, a subrepresentação das mulheres é uma constante entre os que prestaram depoimento à Inquisição portuguesa: dos 354 depoimentos analisados por Lobo e Oliveira (2013), 30,1\% eram de mulheres; dos 348 analisados por Sartori (2016), 21\% eram de mulheres e, mesmo no estudo de Marquilhas (2000), que se estendeu por todo o século XVII português e contou com um corpus de 5.279 depoimentos, a presença feminina atingiu apenas $26 \%$ do total. Trata-se, sem dúvida, de uma subrepresentação significativa, que expressa a realidade de inibição e recolhimento em que viviam as mulheres, quer na Metrópole, quer na Colônia, tolhidas do convívio social mais amplo.

Para além da desigual representação masculina e feminina na amostra, outro aspecto se destaca: as taxas de assinaturas entre homens e mulheres foram proporcionalmente inversas; enquanto $91,5 \%$ dos homens assinaram alfabeticamente o seu nome, 95,5\% das mulheres não o fizeram. Praticamente o mesmo se atestou nos estudos que estão sendo cotejados: no de Lobo e Oliveira (2013), havia 93,4\% de homens assinantes e 84,5\% de mulheres não assinantes e, no de Sartori (2016), 92\% de homens assinantes e 93\% de mulheres não assinantes; apenas no de Marquilhas (2000), o contraste foi um pouco menos significativo: $78,4 \%$ de homens assinantes e $91,6 \%$ de mulheres não assinantes.

Não se pode atestar, a partir de tais resultados, que as mulheres estivessem quase universalmente à margem do mundo das letras. É sabido que, no Antigo Regime, algumas poderiam dominar plenamente a leitura, embora não soubessem escrever, por ser a escrita, aos olhos do homem moderno, "inútil e perigosa para o sexo feminino" (CHARTIER, 2004, p. 117). No Antigo Regime, as taxas de assinaturas de mulheres estarão, portanto, sempre aquém da porcentagem de mulheres leitoras, pois, mesmo nos estratos sociais mais altos, muitas nunca aprenderam a escrever. Marquilhas (2000, p. 118) esclarece que

\footnotetext{
A raiz desta constante estava na própria educação feminina, que não inclúa, à partida, a transmissão da capacidade da escrita: Rafael Bluteau dizia no Vocabulario Portuguez, $e$ Latino que o conceito de Mestra era o de Mulher que ensina meninas a ler, cozer, etc., sem referência explícita ao ensino da escrita; e, com efeito, entre as mulheres que prestam depoimento ao Santo Ofício português, figura mesmo uma mestra de meninas que não assina no final, por não saber escrever.
} 
Aqui, vale referir ainda que muitas mulheres, mesmo não sendo socialmente reconhecidas como mestras, foram de fato no espaço doméstico, como o exemplifica a própria mãe do Padre Antônio Vieira. Segundo Azevedo (2008, pp. 21-22), biógrafo do jesuíta, tendo Cristóvão de Ravasco, seu pai, partido no ano de 1609 para a Bahia, a fim de ocupar um cargo na Relação, permaneceram Vieira, até então filho único, e sua mãe, Maria de Azevedo, sozinhos em Lisboa até o ano de 1612, quando o pai retorna. No ano de 1614, estando Vieira com seis anos de idade, toda a família parte para a Bahia. Na ausência do pai, a reclusão de Maria de Azevedo tornara-se ainda maior, limitando-se ela a sair de casa apenas para as missas. Segundo o próprio jesuíta, sua mãe teria sido sua mestra de ler e escrever. Mesmo sendo quase impossível reconstruir a história do ensino elementar centrado na unidade familiar e no qual a mulher terá tido papel preponderante, não se pode desconhecer a sua importância quanto mais se recua no tempo.

E sobre Maria da Grã de Mendoça, a única mulher assinante nos livros da segunda visitação do Santo Ofício à Bahia, que informações fornecem sobre ela os dados registrados pelo notário? Trata-se de uma portuguesa, branca, cristã-velha, viúva, com idade avançada de 70 anos e residente em Salvador. Não é mencionado quem foi seu esposo e nem se, ao longo da vida, tivera alguma ocupação, razão pela qual não é possível situá-la na hierarquia social. Terão perfil distinto do seu as 21 mulheres não assinantes da amostra? 


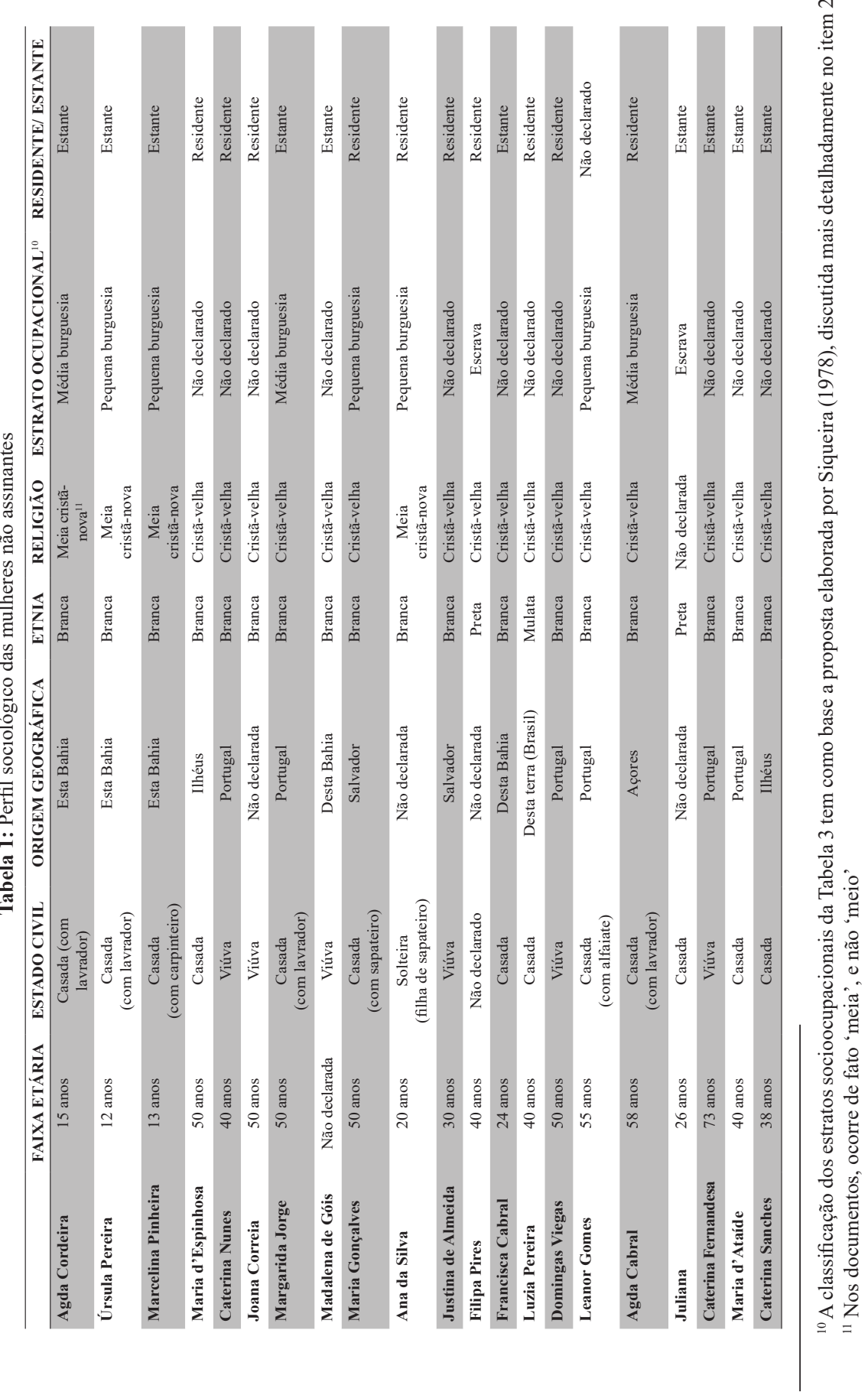


No que se refere ao perfil das mulheres não assinantes, observa-se que: 1) 18 são brancas, 2 pretas e 1 mulata; 2) as pretas são escravas e não há informação sobre sua origem geográfica, sendo uma casada e uma de estado civil não declarado; 3) a mulata, natural "desta terra", era casada, mas não há informação se teria exercido algum ofício nem sobre o ofício exercido pelo marido, o que não permite situá-la na hierarquia social; 4) quanto às brancas, largamente predominantes, afora as duas cuja origem geográfica não é declarada, 9 são nascidas no Brasil, 6 em Portugal e uma nos Açores; 5) não há, entre as brancas, nenhuma da grande burguesia; 6) finalmente, ainda quanto às brancas, predominam as cristãs-velhas ${ }^{12}$, havendo ainda entre elas três meias cristãs-novas.

Nos livros da primeira visitação analisados por Lobo e Oliveira (2013) e Sartori (2016), a presença feminina, em termos absolutos, é muito mais significativa - 110 e 68 mulheres, respectivamente -, assim como também é mais diversificado o seu perfil sociológico, sobre o qual se destacam os seguintes aspectos: 1) a taxa de assinaturas entre as mulheres nascidas no Brasil foi, em ambos os estudos, superior à das mulheres nascidas em Portugal - em Lobo e Oliveira (2013), 22,2\% das brasileiras são assinantes contra 12,1\% das portuguesas; em Sartori (2016), 11\% das brasileiras são assinantes contra 5\% das portuguesas; 2) a taxa de assinaturas entre as cristãs-novas foi, em ambos os estudos, superior à observada entre as cristãs-velhas - em Lobo e Oliveira (2013), 66,7\%\% das cristãs-novas são assinantes contra 12\% das cristãs-velhas; em Sartori (2016), 33\% das cristãs-novas são assinantes contra 5\% das cristãs-velhas; 3) entre as nascidas no Brasil, os dados da primeira visitação, diferentemente do que se observou na segunda, revelam a presença de mamelucas, entre as quais despontam algumas assinantes - em Lobo e Oliveira (2013), das nove mamelucas, uma, Isabel d'Ávila, assinou seu depoimento; em Sartori (2016), das catorze mamelucas, três, Dona Joana d'Albuquerque, Caterina Fernandes e Maria de Heredo assinaram seus depoimentos. Enquanto Isabel d'Ávila e Dona Joana d'Albuquerque são mulheres da elite da terra - a primeira neta do governador-geral Tomé de Sousa e a segunda filha do ilustre Jerônimo d'Albuquerque -, Caterina Fernandes e Maria de Heredo têm ascendência judaica.

Dado o desequilíbrio da amostra no que toca à sua repartição por sexo, a análise se concentrará, de agora por diante, apenas nos homens.

\footnotetext{
${ }^{12}$ Os judeus compulsoriamente convertidos ao cristianismo eram comumente chamados de cristãos-novos, por oposição aos católicos sem ascendência judaica, os cristãos-velhos. Nos livros do século XVII, ao invés de cristãos-novos, utilizava-se mais frequentemente a expressão "da nação", para identificá-los. Havia ainda os filhos de casamentos mistos, designados de várias formas: meio cristão-novo, em parte cristão-novo, cristão-velho que, da parte do pai (ou da mãe), tem raça de cristão-novo, cristão-novo pela parte de seu pai (ou de sua mãe), cristão-novo que tem alguma raça de cristão-velho e até meio da nação.
} 


\subsubsection{Repartição dos homens por lugar de origem}

Entre os 201 homens, predominam os de origem portuguesa, os quais correspondem a $51 \%$ do total. Os nascidos no Brasil, perfazendo 18,4\% da amostra, vêm a seguir. Dos arquipélagos da Madeira e dos Açores são procedentes $9,0 \%$ dos homens. Europeus de proveniência distinta - 05 espanhóis, 01 holandês e 02 belgas - perfazem apenas 4,0\% do total, havendo ainda um indivíduo do continente africano, talvez o mais letrado da amostra, Melchior de Bragança, nascido em Marrocos, cristão-novo, em cuja denúncia se lê:

\footnotetext{
(...) e disse que tiuera em Hispanha por offiçio ensinar a lingoa Hebrea com exposição da sagrada escriptura, como fez na universidade de Alcalá, e na de Salamanca, nas quais leu e ensinou em cadeira publica cõ sallario de seis çentos crusados, e no collegio dos padres da Companhia de Coimbra sem sallario. (LIVRO das Denunciações da Bahia..., 1936).
}

Tabela 2: Homem versus lugar de origem

\begin{tabular}{|c|c|c|}
\hline \multicolumn{3}{|c|}{ HOMENS (201) } \\
\hline \multirow{2}{*}{$\begin{array}{l}\text { PORTUGAL } \\
(103-51 \%)\end{array}$} & Assinantes & $90(87,4 \%)$ \\
\hline & Não assinantes & $13(12,6 \%)$ \\
\hline \multirow{2}{*}{$\begin{array}{l}\text { BRASIL } \\
(37-18,4 \%)\end{array}$} & Assinantes & $36(97,3 \%)$ \\
\hline & Não assinantes & $1(2,7 \%)$ \\
\hline \multirow{2}{*}{$\begin{array}{l}\text { AÇORES } \\
(10-\mathbf{5 , 0} \%)\end{array}$} & Assinantes & $10(100 \%)$ \\
\hline & Não assinantes & --- \\
\hline \multirow{2}{*}{$\begin{array}{l}\text { MADEIRA } \\
(8-4,0 \%)\end{array}$} & Assinantes & $8(100 \%)$ \\
\hline & Não assinantes & --- \\
\hline \multirow{2}{*}{$\begin{array}{l}\text { ESPANHA } \\
(5-2,5 \%)\end{array}$} & Assinantes & $5(100 \%)$ \\
\hline & Não assinantes & --- \\
\hline \multirow{2}{*}{$\begin{array}{l}\text { HOLANDA } \\
(1-0,5 \%)\end{array}$} & Assinantes & $1(100 \%)$ \\
\hline & Não assinantes & --- \\
\hline \multirow{2}{*}{$\begin{array}{l}\text { BÉLGICA } \\
(2-1 \%)\end{array}$} & Assinantes & $2(100 \%)$ \\
\hline & Não assinantes & --- \\
\hline \multirow{2}{*}{$\begin{array}{l}\text { MARROCOS } \\
(1-\mathbf{0 , 5} \%)\end{array}$} & Assinantes & $1(100 \%)$ \\
\hline & Não assinantes & --- \\
\hline \multirow{2}{*}{$\begin{array}{l}\text { NÃO IDENTIFICADO } \\
(34-16,9 \%)\end{array}$} & Assinantes & $31(91,2 \%)$ \\
\hline & Não assinantes & $3(8,8 \%)$ \\
\hline
\end{tabular}

Partindo da média geral anteriormente apresentada de 91,5\% de assinantes entre os homens, observa-se que o percentual de assinaturas entre os portugueses é um pouco inferior à média, ou seja, $87,4 \%$, ao passo que os brasileiros se situam um pouco acima da média, sendo $97,3 \%$ assinantes. A distância entre assinantes portugueses e brasileiros é de 10 pontos percentuais. 
No mesmo sentido já apontavam os dados da primeira visitação. Os resultados obtidos por Lobo e Oliveira (2013) indicam 93,4\% de portugueses assinantes versus $96 \%$ brasileiros e os obtidos por Sartori (2016) revelam 91\% dos portugueses assinando versus $98 \%$ dos brasileiros.

\subsubsection{Repartição dos homens por etnia}

Entre os 201 homens, havia 177 brancos, 06 não brancos e 18 não identificados do ponto de vista étnico. A amostra é, portanto, integrada predominantemente por brancos, afirmação que se faz por inferência, já que o branco era o "não marcado". Desses 177, 103 eram portugueses, sendo $91(88,3 \%)$ assinantes e $12(11,7 \%)$ não assinantes; 28 eram brasileiros, todos assinantes; 17 eram provenientes dos Açores e da Madeira, também todos assinantes e, finalmente, também assinaram os 4 brancos espanhóis, o branco holandês e o belga. Abaixo, desdobram-se os dados sociológicos dos homens mamelucos e mulatos: 


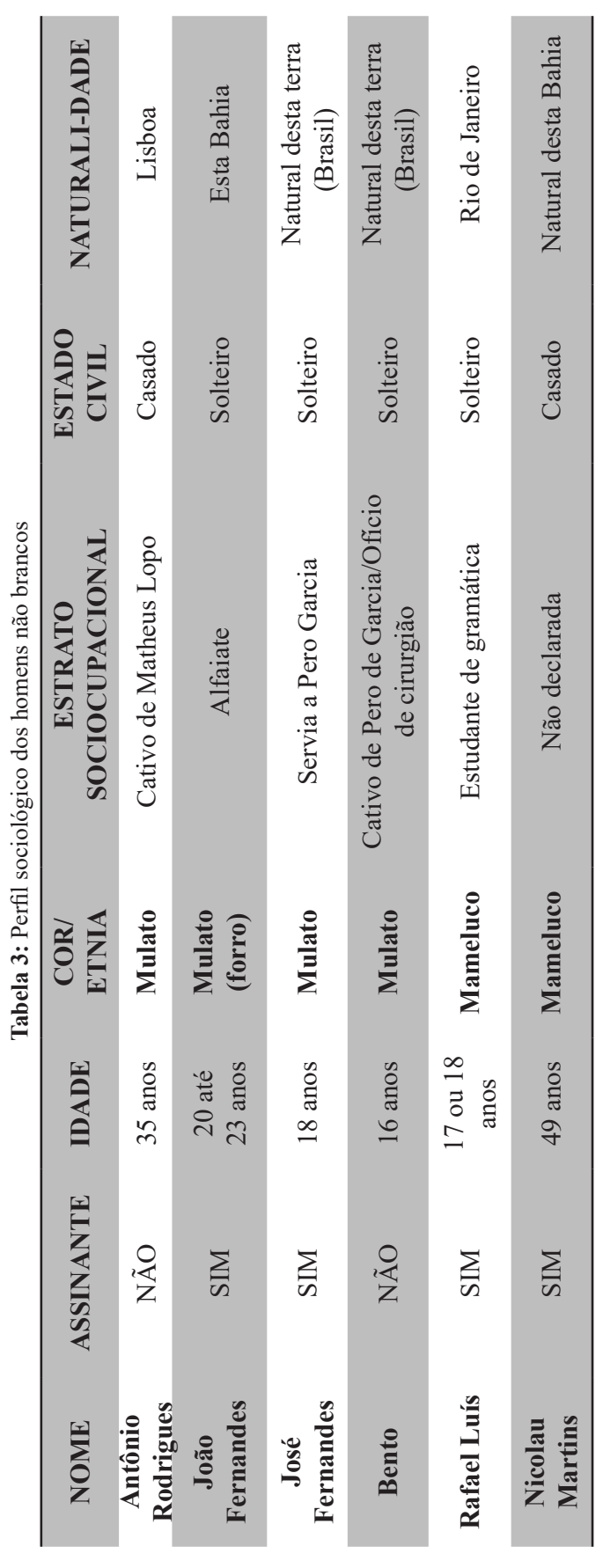


Entre os mestiços, um era de origem portuguesa, mulato, escravo e não assinante; os demais, nascidos no Brasil. Entre estes, os dois mamelucos - um, inclusive, estudante de gramática no Colégio da Companhia de Jesus - sabiam assinar, assim como o sabiam dois dos três mulatos. Com relação ao total dos quatro mulatos, não assinam justamente os escravos e assinam o alfaiate e o que servia a Pero Garcia, não sendo, porém, seu escravo.

Quanto à primeira visitação, na amostra de Lobo e Oliveira (2013), estavam 15 mamelucos, todos assinantes, e 2 índios, que não assinavam. Já na analisada por Sartori (2016), estavam 17 mamelucos, todos assinantes, três mulatos, sendo dois assinantes e um não assinante e, finalmente, 2 cafuzos, sendo 1 assinante.

$\mathrm{O}$ número de mamelucos entre os depoentes/confitentes da segunda visitação é incipiente. Contudo, se se considerar que os 32 mamelucos que se apresentaram à Mesa do Santo Ofício, na primeira visitação, eram todos assinantes, confirmase que aprender a ler e escrever não era um privilégio apenas de homens brancos portugueses e brasileiros, mas uma realidade entre filhos homens mestiços de homens brancos e mulheres índias nas capitanias analisadas.

\subsubsection{Repartição dos homens por condição religiosa}

A Tabela 4 apresenta a distribuição dos indivíduos de acordo com sua condição religiosa:

Tabela 4: Homens versus condição religiosa

\begin{tabular}{lcc}
\hline & HOMENS (201) & \\
\hline $\begin{array}{l}\text { CRISTÃOS-VELHOS } \\
(\mathbf{1 6 4}-\mathbf{8 1 , 6 \% )}\end{array}$ & Assinantes & $150(91,5 \%)$ \\
CRISTÃOS-NOVOS & Não assinantes & $14(8,5 \%)$ \\
$\mathbf{( 2 7 - \mathbf { 1 3 , 4 } \% )}$ & Assinantes & $25(92,6 \%)$ \\
EM PARTE CRISTÃOS-NOVOS & Não assinantes & $2(7,4 \%)$ \\
$\mathbf{( 6 - 3 , 0 \% )}$ & Assinantes & $5(83 \%)$ \\
CALVINISTAS & Não assinantes & $1(17 \%)$ \\
$\mathbf{( 1 - 0 , 5 0 \% )}$ & Assinantes & $1(100 \%)$ \\
NÃO DECLARADA & Não assinantes & 0 \\
$\mathbf{( 3 - 1 , 5 \% )}$ & Assinantes & $3(100 \%)$ \\
\hline
\end{tabular}

A expressiva maioria dos homens a prestar depoimento foi de cristãosvelhos - ao todo, 164 indivíduos, que representaram $81,6 \%$ do total. A ausência de um número significativo de cristãos-novos entre os depoentes pode ser compreendida, quando se tem em vista que estes se encontravam em uma posição de intimidação perante a Inquisição Portuguesa, já que eram os primeiros suspeitos do principal crime que o Tribunal perseguia: o judaísmo. Foi grande a lista de pessoas que compareceram perante o Santo Ofício para denunciar os indivíduos que não trabalhavam aos sábados, usavam roupas novas e lavadas nesse dia, ou conservavam outros hábitos considerados de judeus. 
Cadernos de ESTUDOS LINGUIISTICOS (58.2) - mai./ago. 2016

A seguir aos cristãos-velhos, vêm os cristãos-novos, representando $13,4 \%$ do total. O percentual de assinantes entre cristãos-velhos e novos é equivalente: entre os velhos, 91,5\% eram assinantes; entre os novos, 92,6\%. Houve seis testemunhas que se declararam em parte cristãos-novos, sendo cinco desses assinantes. Acham-se ainda, entre os assinantes, três indivíduos que não tiveram a condição religiosa declarada e um que se declarou calvinista, o holandês João de Araújo, que confessava ter sido batizado "conforme o uso, costume, e tensão da gente da sua terra, e ensinado e instruído desde que teue uso de razão na çeita de Caluino por mandado e consentimento de seu pay e may" e declarava que pretendia se converter à fé católica "e deixar seus hereticos erros" (Livro das Confissões e Reconciliações, 1618).

Nesta amostra do século XVII, não se confirmam os indícios apontados para o século XVI, no sentido da interferência da variável condição religiosa favoravelmente aos cristãos-novos. No estudo de Lobo e Oliveira (2013), 100\% dos cristãos-novos assinam, enquanto $95 \%$ dos cristãos-velhos o fazem; no estudo de Sartori (2016), também 100\% dos cristãos-novos assinam e, entre os velhos, $91 \%$.

\subsubsection{Repartição dos homens por estratos socioocupacionais}

A hierarquização de sociedades do passado em estratos socioocupacionais é uma das operações de categorização mais difíceis de realizar, revelando-se sempre como um desafio. Aqui se abre mão da formulação de uma proposta original em favor da elaborada por Siqueira (1978), que tem a vantagem de ter sido produzida exatamente a partir da análise dos documentos legados pelas duas primeiras visitações do Santo Ofício ao Brasil.

Em sua classificação, Siqueira dividiu a sociedade colonial brasileira dos séculos XVI e XVII em três grandes grupos: (i) o da grande burguesia, que abarcava senhores de engenhos, grandes comerciantes e ainda o alto clero, que não raro possuía terras e engenhos; (ii) o da pequena e média burguesia, bastante heterogêneo, no qual se encontravam artesãos, assalariados, burocratas, homens do mar, pequenos lavradores, liberais, mercadores de loja e clero médio e baixo e, finalmente, (iii) o grupo do povo, onde estavam indivíduos que trabalhavam em pequenos ofícios, e também os escravos, responsáveis por quase todas as atividades nas lavouras e engenhos ${ }^{13}$. Apresenta-se a seguir a distribuição dos homens assinantes e não assinantes, segundo seu estrato socioocupacional ${ }^{14}$.

${ }^{13}$ Sua taxonomia sofreu apenas as seguintes modificações: (i) no grupo da pequena e média burguesia, incluíram-se os estratos 'familiares do Santo Ofício' e 'ocupação militar', à exceção dos soldados, incluídos em 'pequenos ofícios', portanto, entre o povo; (ii) em cada um dos três grandes grupos sociais, foram destacados os indivíduos que declararam dupla ocupação; (iii) os indivíduos sem ofício, ou de ofício não declarado, que incluídos por Siqueira no terceiro grupo, do povo, foram retirados desse grupo. Veja-se a nota abaixo.

14 É expressiva a quantidade de depoentes cuja profissão/ocupação não é declarada, correspondendo a 62 indivíduos, ou seja, 30,8\% do total. 
LOBO, SARTORI \& SOARES - O aporte das fontes inquisitoriais para uma história da ...

Tabela 5: Grande burguesia

\section{ESTRATO SOCIOCUPACIONAL ASSINANTES NÃO ASSINANTES}

\begin{tabular}{lcc} 
Senhores de engenho / donos de fazenda & $2(100 \%)$ & 0 \\
Mercadores & $16(100 \%)$ & 0 \\
$\begin{array}{l}\text { Indivíduos de dupla ocupação de distintos } \\
\text { estratos sociais (alta burguesia e pequena/ } \\
\text { média burguesia) }\end{array}$ & $2(100 \%)$ & 0 \\
\hline
\end{tabular}

Os integrantes da grande burguesia estão representados por 20 indivíduos, correspondentes a 9,9\% do total da amostra, sendo a maior parte deles mercadores e não havendo, nesta amostra, representantes do alto clero. Todos indistintamente são assinantes, o que indicia que, se a elite social e econômica não correspondia necessariamente a uma elite cultural (e provavelmente não correspondia), os integrantes do mais alto estrato da população colonial tinham acesso, generalizadamente, à leitura e à escrita, ainda que, certamente, com graus muito variáveis de letramento. Apesar de se tratar de afirmação um tanto generalizante, Romanelli (2002, p. 33) assegura que a escola era frequentada apenas pelos filhos homens que não os primogênitos, uma vez que os primogênitos deveriam herdar a responsabilidade pelos negócios paternos e recebiam, portanto, apenas uma "rudimentar educação escolar" e "a preparação para assumir a direção do clã, da família e dos negócios".

Tabela 6: Média e pequena burguesia

\begin{tabular}{lcc}
\hline \multicolumn{1}{c}{ ESTRATO SOCIOCUPACIONAL } & ASSINANTES & NÃO ASSINANTES \\
Clero (médio e baixo) & $14(100 \%)$ & 0 \\
Pequenos lavradores & $17(100 \%)$ & 0 \\
\hline Burocratas & $17(100 \%)$ & 0 \\
\hline Liberais & $14(100 \%)$ & 0 \\
\hline Mercadores de loja & $2(100 \%)$ & 0 \\
Familiares do Santo Ofício & $2(100 \%)$ & 0 \\
Vive de sua fazenda & $1(100 \%)$ & $1(17,7 \%)$ \\
\hline Homens do mar & $1(100 \%)$ & $4(30,8 \%)$ \\
Ocupação militar (média e alta patente) & $5(83,3 \%)$ & $4(36,4 \%)$ \\
\hline $\begin{array}{l}\text { Assalariados } \\
\text { Artesãos }\end{array}$ & $9(69,2 \%)$ & \\
$\begin{array}{l}\text { Indivíduos de dupla ocupação da pequena e } \\
\text { média burguesia }\end{array}$ & $5(63,6 \%)$ & \\
\hline $\begin{array}{l}\text { Indivíduos de dupla ocupação de distintos } \\
\text { estratos sociais (da pequena e média } \\
\text { burguesia e do povo) }\end{array}$ & $1(100 \%)$ & \\
\hline
\end{tabular}


Cadernos de ESTUDOS LINGUÍSTICOS (58.2) - mai./ago. 2016

São 104 os homens que representam estratos sociais da média e da pequena burguesia, o que perfaz $51,7 \%$ da amostra, aproximadamente o quíntuplo dos homens da grande burguesia. Entre eles, a taxa de assinaturas, se não chega à universalidade observada para o grupo anterior, é ainda bastante alta, atingindo $91,3 \%$. Como se verá a seguir, há, contudo, uma clivagem entre homens da média burguesia, $100 \%$ assinantes, com exceção de um indivíduo, e os da pequena burguesia, com $66,7 \%$ de assinantes.

Os homens do clero médio e baixo, os pequenos lavradores, os burocratas, os liberais, os mercadores de loja, o familiar do Santo Ofício, o que "vivia da sua fazenda", o homem do mar, bem como os que tinham dupla ocupação, mostraramse todos capazes de assinar. Se não há surpresa quanto aos homens do médio e baixo clero (a cuja formação eram prioritariamente destinadas as classes dos colégios da Companhia de Jesus, tornando-se alguns deles professores dos mesmos colégios da Companhia), quanto aos burocratas (representados por funcionários públicos, como os escrivães, por exemplo), quanto aos liberais (dentre os quais estavam licenciados, professores laicos e estudantes ${ }^{15}$ ), quanto aos mercadores de loja, nem mesmo quanto ao familiar do Santo Ofício, "ao que vivia da sua fazenda" e ao homem do mar (representado por um mestre de navio), causa estranheza aos olhos do leitor contemporâneo ser o estrato dos pequenos lavradores - com 17 indivíduos - constituído por $100 \%$ de assinantes. Deve-se, porém, ter em vista que, no Brasil colonial, não eram designados de lavradores os trabalhadores rurais, e, sim, os donos ou arrendatários de terra, colonos que teriam, portanto, recursos para investimentos na produção açucareira, tais como a aquisição de muitos escravos e do gado necessário para o trabalho na lavoura. A função de trabalhador agrícola seria reservada aos inúmeros escravizados, que plantavam, colhiam e transportavam a cana, administrados ou, por vezes, auxiliados por alguns poucos trabalhadores livres, como os feitores.

Deste grupo, os estratos que não apresentaram unicamente assinantes foram, por um lado, os militares, de média ou alta patente - integrantes da média burguesia - e, por outro, assalariados (caixeiros, marinheiros, mestres de açúcar, feitores...) e os artesãos (sapateiros, carpinteiros, alfaiates...) - integrantes da pequena burguesia. Os percentuais de assinantes entre assalariados e artesãos são ainda altos, quando se tem em vista que desempenham atividades que não exigem, diretamente, algum nível de letramento, ainda que possam, eventualmente, favorecer o aprendizado da leitura e da escrita.

Chega-se, finalmente, abaixo, aos estratos socioocupacionais do povo:

${ }^{15}$ Há 10 estudantes do Colégio da Companhia de Jesus, sendo todos brancos, à exceção de 1 mameluco. Apresentam idade variável entre 13 e 28 anos, sendo 2 de Lisboa, 1 da Ilha de São Miguel (Açores), 1 do Rio de Janeiro, 3 nascidos em Salvador e 3 de naturalidade não declarada. 1 é filho de um cortador de carne ("povo"), 2 são filhos de artesãos (pequena burguesia) e 2, de burocratas (média burguesia), não havendo, para os demais, informação sobre a atividade exercida pelo pai. 
LOBO, SARTORI \& SOARES - O aporte das fontes inquisitoriais para uma história da ...

Tabela 8: Povo

\begin{tabular}{lcc}
\hline \multicolumn{1}{c}{ ESTRATO SOCIOCUPACIONAL } & ASSINANTES & NÃO ASSINANTES \\
\hline Pequenos ofícios & $10(76,9 \%)$ & $3(23,1 \%)$ \\
Escravos & 0 & $2(100 \%)$ \\
\hline
\end{tabular}

Os 15 homens do povo perfazem 7,5\% da amostra. Entre eles, a média de assinaturas é de 66,7\%. Assalariados e artesãos equiparam-se, assim, aos que desempenhavam pequenos ofícios, como criados, barbeiros e soldados... Os escravos, apesar de sub-representados, são, como esperado, não assinantes.

\section{PALAVRAS FINAIS}

Segundo apontam os dados da historiografia, nos séculos XVI e XVII, a sociedade brasileira seria constituída, em sua maioria, por índios e negros, sendo os brancos correspondentes a aproximadamente um terço da população (cf. COUTO, 1998). Apesar de essa parcela majoritária da sociedade, composta por índios e negros, estar sub-representada na amostra aqui analisada, não se está a crer que esse fato invalide os aportes das fontes inquisitoriais para uma história da difusão social da leitura e da escrita no Brasil. É sabido que índios e negros ocupavam uma posição de marginalidade, daí ser esperado que não só não comparecessem perante o Santo Ofício, mas, ao fazê-lo, que não se mostrassem capazes de assinar seus depoimentos. Resultado semelhante era esperado entre os mulatos: poucos deveriam depor, e poucos, entre esses, saberiam assinar - o que também se observou na fonte analisada, ainda que já se veja, entre esses, alguma domínio da capacidade de assinar.

Entre os mamelucos, observou-se que, tanto nos dados do século XVII, quanto naqueles referentes ao século XVI, que contêm uma amostra mais expressiva dessa etnia, o seu comportamento, em relação à habilidade de assinar difere substancialmente do das etnias supracitadas, que se encontravam à margem da população: os mamelucos, assim como os homens brancos, exibiram níveis constantemente altos de assinantes - o que parece indicar que estes teriam, nas regiões analisadas, um status social muito mais próximo ao do pai branco do que ao da mãe ou avó índia, o que lhes favoreceria a aquisição da língua portuguesa como língua materna ou como segunda língua, bem como de práticas de leitura e escrita.

A tímida presença feminina nas fontes inquisitoriais não impede a constatação, bastante clara, do diferente comportamento que exibiam homens e mulheres perante o Santo Ofício: os percentuais de assinaturas entre homens e mulheres foram proporcionalmente inversos; enquanto $91,5 \%$ dos homens assinaram alfabeticamente o seu nome, na amostra do século XVII, 95,5\% das mulheres não o fizeram - situação semelhante à que se encontra nas amostras da população brasileira do século XVI e ainda na análise de Marquilhas, referente à sociedade portuguesa. Esses índices de assinaturas, embora não possam dar conta de especificidades no processo de letramento entre mulheres no período 
analisado - como a possibilidade de estas adquirirem a capacidade de ler, mas não de escrever -, são expressivos da realidade que parecia ser a mais comum e geral, que se perpetuou por séculos na história do Brasil e do mundo ocidental, em que as mulheres se encontravam à margem de práticas sociais como as de letramento.

Quanto ao letramento de homens brancos, é preciso observar que o percentual geral de assinantes homens encontrado, de 91,5\%, é não só extremamente alto, mas mais alto do que aquele encontrado por Marquilhas, de 78,4\%, entre os homens portugueses. Esses dados mostram-se ainda mais inusitados quando observado que não apenas os homens da elite colonial - senhores de engenho, mercadores e alto clero - assinavam seus depoimentos, mas também o faziam com frequência os integrantes dos setores médios e baixos da sociedade - estando aí incluídos o clero médio e baixo, os pequenos lavradores, os burocratas, os liberais, os mercadores de loja, os que viviam de sua fazenda, os homens do mar, os que possuíam uma ocupação militar, os assalariados, os artesãos e os indivíduos que possuíam pequenos ofícios, como criados, barbeiros e soldados -, havendo, portanto, um único estrato da população que se mostrou completamente alheio às práticas de escrita: o grupo dos escravos.

A amostra aqui analisada revela, portanto, uma parcela da sociedade colonial constituída por homens brancos (e, quiçá, por seus filhos homens com mulheres indígenas), cristãos-velhos e novos, integrantes, principalmente, de setores médios da sociedade, os quais compunham, juntamente com os da elite colonial e ainda com parte do povo, um seleto grupo de indivíduos com familiaridade com a tecnologia da escrita, certamente indispensável, inclusive, no caso de serem brancos europeus, para a comunicação por cartas com os seus que ficaram na distante Metrópole.

\section{$\overline{\text { REFERÊNCIAS }}$}

AZEVEDO, João Lúcio de (2008). História de Antônio Vieira. Tomo 1. São Paulo: Alameda.

ARQUIVO NACIONAL DA TORRE DO TOMBO (ANTT). Site do ANTT. Lisboa: ANTT, 2005. Atualização diária. Disponível em: <http://antt.dgarq.gov.pt/>. Acesso em: 11 set. 2012.

CASTILlO GÓMEZ, Antonio; SÁEZ, Carlos (1994). Paleografía versus alfabetización. Reflexiones sobre historia social de la cultura escrita, SIGNO. Revista de Historia de la Cultura Escrita, n. 1, Alcalá de Henares, p.p. 133-168.

CHARTIER, Roger (2004). "As práticas da escrita". In: ARIÈS, Philippe; CHARTIER, Roger (Orgs.). História da vida privada: da Renascença ao século das luzes. São Paulo: Companhia das Letras.

COUTO, Jorge (1998). A construção do Brasil: ameríndios, portugueses e africanos, do início do povoamento a finais de Quinhentos. Lisboa: Edições Cosmos.

SEGUNDA Visitação do Santo Ofício às partes do Brasil pelo Inquisidor e Visitador Marcos Teixeira: Livro das Confissões e Ratificações da Bahia, 1618-1620. Introdução de Eduardo de Oliveira França Sônia Siqueira. Anais do Museu Paulista, t. XVII, 1963. 
LOBO, SARTORI \& SOARES - O aporte das fontes inquisitoriais para uma história da ...

GALVÃO, Ana Maria de Oliveira (2010). "História das culturas do escrito: tendências e possibilidades de pesquisa". In: MARINHO, Marildes; CARVALHO; Gilcinei Teodoro (Org.). Cultura escrita e letramento. Belo Horizonte: Editora da UFMG.

HOUAISS, Antônio (1985). A língua portuguesa no Brasil. Rio de Janeiro, UNIBRADE.

LIVRO das Denunciações da Bahia que se fizerão na Visitação do Santo Officio á Cidade Salvador da Bahia de Todos os Santos do Estado do Brasil, no anno de 1618. Introdução de Rodolfo Garcia. Annaes da Bibliotheca Nacional do Rio de Janeiro, v. XLIX, 1936.

LANGELI, Attilio Bartoli (1996). Historia del alfabetismo y método cuantitativo, SIGNO. Revista de Historia de la Cultura Escrita, n. 3, Alcalá de Henares, p.p. 87-106.

LOBO, Tânia; OLIVEIRA, Klebson (2013). "Ainda aos olhos da Inquisição: novos dados sobre níveis de alfabetização na Bahia em finais de quinhentos". In: ÁLVAREZ, Rosario; MARTINS, Ana Maria; MONTEAGUDO, Henrique; RAMOS, Maria Ana (Org.). Ao sabor do texto. Estudos dedicados a Ivo Castro. Santiago de Compostela: Universidade de Santiago de Compostela, Servizo de Publicacións e Intercambio Científico. p.p. 10-25.

MARQUILHAS, Rita (2000). A faculdade das letras: leitura e escrita em Portugal, séc. XVII. Lisboa: Imprensa Nacional - Casa da Moeda.

MATTOS E SILVA, Rosa Virgínia (1998). "Ideias para a história do português brasileiro: fragmentos para uma composição posterior". In: CASTILHO, Ataliba Teixeira de (Org.). Para a história do português brasileiro. V. 1 Primeiras idéias. São Paulo: Humanitas/FAPESP. p.p. 21-52.

NASCIMENTO, Anna Amélia Vieira do (1994). Patriarcado e religião: as enclausuradas clarissas do Convento do Desterro da Bahia, 1677-1890. Salvador: Conselho Estadual de Cultura.

RODRÍGUEZ, Marie-Christine; BENNASSAR, Bartolomé (1978). Signatures et niveau culturel des témoins et accusés dans les procès d'Inquisition du ressort du tribunal de Tolède (1525-1817) et du ressort du tribunal de Cordoue (1595-1632). Caravelle, n. 31, p.p. 14-46

ROMANELli, Otaíza de Oliveira (2002). História da educação no Brasil: 1930/1973. 27 ed. Petrópolis: Vozes.

SARTORI, Ana (2016). Pela pena do Santo Ofício: difusão social da escrita nas capitanias de Pernambuco, Itamaracá e Paraíba em finais Quinhentos. Tese (Doutorado em Língua e Cultura). Universidade Federal da Bahia.

SIQUEIRA, Sônia Aparecida de (1978). A Inquisição portuguesa e a sociedade colonial. São Paulo: Ática. 